\title{
Acute acalculous cholecystitis due to an incarcerated epigastric hernia
}

\author{
Gideon Goldman, Alon J. Rafael and Kashtan Hanoch
}

Department of Surgery 'A', Ichilov Hospital, Tel Aviv Medical Center and The Sackler School of Medicine, Tel Aviv, Israel

\begin{abstract}
Summary: A case of a 96 year old woman with an incarcerated gallbladder in an epigastric hernia causing acute acalculous cholecystitis is described. At operation the gallbladder was replaced in its anatomical site and the hernia was repaired. This unique case of acute acalculous cholecystitis demonstrates cystic duct obstruction and cystic vessel compression as possible aetiologies for this pathology.
\end{abstract}

\section{Introduction}

Acute acalculous cholecystitis has been reported with increasing frequency (Glenn \& Becker, 1982). This entity is most often described in patients who have been injured or have experienced sepsis or prolonged postoperative complications (Rice et al., 1980; Rubio et al., 1981). Other aetiological factors are scarlet fever (Dickinson et al., 1971), Salmonella infection (Campbell \& Eckman, 1975), as a sequel of burned patients (Munsten et al., 1971), or by activation of factor XII (Becker et al., 1980).

Some authors describe chronic acalculous cholecystitis associated with atherosclerotic cardiovascular disease, diabetes mellitus, pancreatitis, nephrolithiasis, rheumatoid arthritis, viral hepatitis and bronchial asthma (Lee et al., 1984).

We report a unique case of acute acalculous cholecystitis due to a very rare and unusual mechanism.

\section{Case report}

A previously healthy 96 year old woman complained of abdominal pain of sudden onset with nausea and vomiting and $16 \mathrm{~h}$ later developed fever of $38.8^{\circ} \mathrm{C}$ and jaundice. On physical examination the blood pressure was $100 / 60 \mathrm{~mm} \mathrm{Hg}$ and her pulse rate was 100 beats/ min. An incarcerated epigastric hernia was found with focal redness and tenderness, but without signs of diffuse peritoneal irritation. There were no signs of

Correspondence: G. Goldman, M.D., Department of Surgery 'A' Ichilov Hospital, Tel Aviv Medical Center, 6 Weizmann Street, Tel Aviv 64239, Israel

Accepted: 14 May 1985 bowel obstruction either clinically or on plain abdominal X-ray. Laboratory findings were all within normal limits, except for a white cell count of $20 \times 10^{9} / 1$, and slightly raised bilirubin, and alkaline phosphatase levels. Surgery was undertaken and the incarcerated epigastric hernia explored. The content of the hernial sac was a 'floating gallbladder' which was suspended from the liver by a complete mesentery (Figure 1). The gallbladder wall was oedematous with ischaemic areas. The cystic duct and cystic blood vessels were compressed by the hernial ring, causing cystic duct obstruction, no stones were found in the gallbladder. After opening the fascial ring and releasing the cystic structures, the ischaemic signs disap-

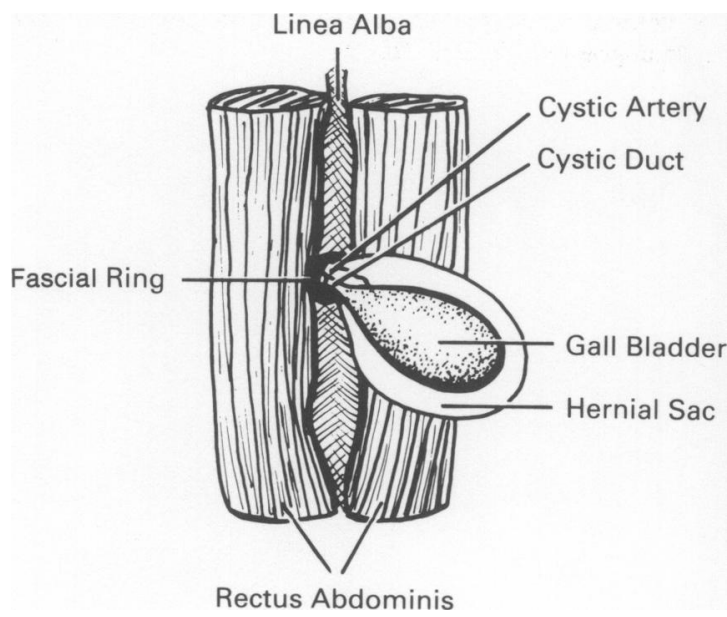

Figure 1 Incarcerated epigastric hernia.

C The Fellowship of Postgraduate Medicine, 1985 
peared and the gallbladder regained its normal colour. The gallbladder was replaced in its anatomical site and the hernia was repaired. The postoperative period was uneventful.

\section{Discussion}

Acute cholecystitis occurs in an acalculous gallbladder in $5 \%$ of patients and is generally superimposed on a major illness or occurs subsequently to a traumatic event such as surgery, major injury or burns. Multiple factors have been proposed as causes of acalculous cholecystitis including prolonged fasting, anaesthesia, analgesia, dehydration, gastrointestinal ileus, multiple blood transfusion and sepsis.

Some authors suggest that the pathogenesis of acalculous cholecystitis in the post-traumatic patient is due to reduction of the blood flow and in the septic

\section{References}

BECKER, C.G., DUBIN, T. \& GLENN, F. (1980). Induction of acute cholecystitis by activation of factor XII. Journal of Experimental Medicine, 151, 8110.

CAMBELL, C.W. \& ECKMAN, M.R. (1975). Acute acalculous cholecystitis caused by salmonella indiana. Journal of the American Medical Association. 233, 815.

DICKINSON, S.J., CORLEY, G. \& SANTULLI, T.V. (1971). Acute cholecystitis as a sequel to scarlet fever. American Journal of Diseases of Childhood, 121, 331.

GLENN, F. (1979). Acute acalculous cholecystitis. Annals of Surgery, 189, 458.

GLENN, F. \& BECKER, C.G. (1982). Acute acalculous cholecystitis, an increasing entity. Annals of Surgery, 195, 131.

JOHNSON, P.E. \& ANDERSSON, A. (1976). Postoperative acalculous cholecystitis. Archives of Surgery, 111, 1097. patient due to septic emboli to the gallbladder (Johnson \& Anderson, 1976; Glenn 1979). Other authors suggest that vasoconstriction of abdominal visceral vessels plays a part (Lygidakis, 1981).

In our patient the incarceration of the gallbladder in the epigastric hernia caused cystic duct obstruction and cystic blood vessel compression, both leading to ischaemic changes in the gallbladder wall. In this case, release of the compression on these structures by opening the fascial ring was sufficient and there was no indication for cholecystectomy.

This unique case demonstates, in vivo, two mechanisms which cause acute cholecystitis. Our patient had cystic duct obstruction which is the chief cause of calculous cholecystitis as well as a vascular occlusion which results in 'ischaemic cholecystitis'. This latter is one of the factors that has been proposed as a possible mechanism causing acalculous cholecystitis.

LEE, A.W., PROUDFOOT, W.H. \& GRIFFEN, W.O. (1984). Acalculous cholecystitis. Surgery, Gynecology and Obstetrics, 159, 33.

LYGIDAKIS, N.J. (1981). Surgery for acalculous cholecystitis an organic and not a functional disease. American Journog of Gastroenterology, 76, 27.

MUNSTER, A.M., GOODWIN, M.N. \& PRUITT, B.A. (1971 Acalculous cholecystitis in burned patients. Americant+ Journal of Surgery, 122, 591.

RICE, J., WILLIAMS, H.C., FLINT, L.M. \& RICHARDSON, J.D. (1980). Post traumatic acalculous cholecystitis. Southern Medical Journal, 73, 14.

RUBIO, P.A., FARREL, E.M. \& VITZU, M. (1981). Postoperative acalculous cholecystitis. International Surgery, 66, 167. 